\title{
A Review on Atomoxetine in the Treatment of Attention Deficit Hyperactivity Disorder
}

\author{
Kattula Rao Vinay Rajan ${ }^{1}$, Sathish Sreenivas P ${ }^{2}$, Pilla S Surya Durga Devi ${ }^{1}$, Penugonda Vineela ${ }^{1}$, Ravisankar Pasam ${ }^{3}$ and Siddartha SRV ${ }^{1}$ \\ ${ }^{1}$ Department of Pharmacy Practice, GIET School of Pharmacy, Rajahmundry, India \\ ${ }^{2}$ Department of Medicine, Rangaraya Medical College, Kakinada, India \\ ${ }^{3}$ Department of Psychiatry, KIMS Amalapuram, India
}

*Corresponding author: Kattula Rao Vinay Rajan, Department of Pharmacy Practice, GIET School of Pharmacy, Rajahmundry, India, Tel: 919703445458; E-mail: kvinayrajan@gmail.com

Received Date: July 8, 2014, Accepted Date: September 23, 2014, Published Date: September 30, 2014

Copyright: (c 2014, Kattula Rao Vinay Rajan et al., This is an open-access article distributed under the terms of the Creative Commons Attribution License, which permits unrestricted use, distribution, and reproduction in any medium, provided the original author and source are credited.

\begin{abstract}
Atomoxetine is a first non-stimulant and the first drug to be licensed for the treatment of Attention Deficit Hyperactivity Disorder (ADHD) in adults and children. Atomoxetine was got approval for treatment of ADHD in the US in November 2002 and in the UK in May 2004. The Mechanism by which atomoxetine acts is unclear, but is expected to be related to its selective inhibition of presynaptic norepinephrine reuptake in the prefrontal cortex. It shows high affinity and selectivity towards norepinephrine receptors, but minimal or no affinity towards muscarinic, serotonergic, cholinergic, and adrenergic receptors, and serotonin and dopamine receptors. As a result atomoxetine is unlikely to have abuse potential or to cause motor tics. Atomoxetine has found to be having a significant role in the treatment of young people who do not respond or develop side-effects to stimulants. Atomoxetine has been shown to be well tolerated in most of the patients. Most of the adverse drug reactions associated with atomoxetine treatment was mild or moderate, and there was a very low incidence of serious adverse events. Very rare but significant side-effects that have been reported include elevated liver enzymes, and motor tics. Atomoxetine offers other advantages such as once daily dosage.
\end{abstract}

Keywords: Atomoxetine; ADHD; OROS methylphenidate; Tic disorder

\section{Introduction}

Atomoxetine is a first non-stimulant drug which selectively inhibits the presynaptic nor-epinephrine receptors with less affinity towards other noradrenergic receptors or for other neurotransmitter receptors and the first drug to be licensed for the treatment of Attention Deficit Hyperactivity Disorder (ADHD) in adults and children. Atomoxetine was got approval for treatment of ADHD in the US in November 2002 and in the UK in May 2004 [1,2] Till now, atomoxetine has been approved for children and adolescents with ADHD in 84 countries and approved for adult use in over 39 countries including the United States [3]. Atomoxetine was previously called tomoxetine, but to avoid the confusion with tamoxifen, the name was later changed to atomoxetine [4]. It was initially developed as an antidepressant with minimum anticholinergic side-effects of tricyclic antidepressants (TCAs), but the antidepressant medications class SSRI's such as fluoxetine offers better therapeutic outcomes, limits the use of atomoxetine as an antidepressant. Atomoxetine shows the potential of efficacy in ADHD and low side-effect profile. Although, atomoxetine takes longer time to produce its effects, it can provide all-day cover and shows adjuvant effects such as mood stabilisation and treatment of initial insomnia. Atomoxetine has found to be having a significant role in the treatment of young people who do not respond or develop side-effects to stimulants and as an alternative for those with co morbid conditions such as anxiety or tic disorder. It is also beneficial for those with sleep problems or substance misuse [5]. Atomoxetine offers other advantages such as once daily dosage, less rebound, and a mild anti-anxiety effect, which may be helpful for management of co morbidity [6]. The NICE guidelines (2008) recommend that atomoxetine should be considered an alternative first-line treatment to methylphenidate in ADHD with these co morbidities and should be used second line for individuals intolerant of or non-responsive to methylphenidate [5].

Multiple double-blind, placebo-controlled studies have been conducted to determine the efficacy and safety of atomoxetine. All of these studies were favour to atomoxetine, suggesting that atomoxetine is clinically and statistically superior to placebo in reducing ADHD symptoms in children and adolescents based on information from parents given to investigators in a structured interview. Also, in most trials, the adverse events were noted in less than 5\% recommending that atomoxetine is safe and well tolerated in children and adolescents with ADHD [7].

\section{Clinical Pharmacology}

\section{Pharmacodynamics}

Evidence from the neurobiological science suggests that drugs that have an action on dopamine and noradrenalin may exhibit potential therapeutic efficacy in ADHD [1]. The noradrenergic system is responsible for sustained attention, learning, cognition, and adaptive response. Attention regulation and inhibition are under the control of right dorsal pre-frontal cortex of the brain [8]. The Mechanism by which atomoxetine acts is unclear, but is expected to be related to its selective inhibition of presynaptic norepinephrine reuptake in the prefrontal cortex. It shows high affinity and selectivity towards norepinephrine receptors, but minimal or no affinity towards other 
neurotransmitter receptors [9]. It has much more affinity for norepinephrine and 290 -fold lower affinity for dopamine receptors than norepinephrine. Mechanistically, blocking of the NE transporter restricts synaptic clearance of $\mathrm{NE}$ and thereby raising synaptic NE concentrations in noradrenergic pathways. In animal studies, atomoxetine has been shown to selectively increase dopamine (DA) to a similar extent as NE in the PFC, due to region-specific shared monoamine uptake inhibition, while not altering DA in other dopamine rich brain regions such as nucleus accumbens and striatum [10]. It has lesser affinity for muscarinic, serotonergic, cholinergic, and adrenergic receptors, and serotonin and dopamine receptors [8]. As a result atomoxetine is unlikely to have abuse potential or to cause motor tics [1].

\section{Pharmacokinetics}

\section{Absorption}

Atomoxetine is readily absorbed from the gastrointestinal tract after oral administration (range 63\%-94\%); and has an absolute bioavailability of $94 \%$ in Poor Metabolizers (PMs) and $63 \%$ in Extensive Metabolizers (EMs). Its bioavailability is not significantly affected by food, and the drug can be administered with or without food $[10,11]$. Food rich in fat decreases the rate of absorption but has no impact on the amount of absorption. Peak plasma levels were attained after 4-4.5 hours with high fat meal [8]. The average time to reach peak plasma concentrations (Cmax) at steady state was approximately 1-2 hours. At steady state, Cmax for atomoxetine was almost 6-times higher in PMs than in EMs and mean area under the plasma concentration-time curve was approximately 8-fold higher [11].

\section{Distribution}

Nearly $98 \%$ Atomoxetine is protein bound, specifically to albumin [10]. After the intravenous administration, at steady state the volume of distribution was found to be $0.85 \mathrm{~L} / \mathrm{kg}$ and is same in both PMs and EMs. The apparent volume of distribution was found to be $1.02 \mathrm{~L} / \mathrm{kg}$ in PMs and $2.33 \mathrm{~L} / \mathrm{kg}$ in Ems [11]. The active metabolite, 4hydroxyatomoxetine, is about $67 \%$ protein bound. The medication is majorly distributed into total body water [8].

\section{Metabolism}

Atomoxetine is metabolized in to 4-hydroxyatomoxetine by oxidation via genetically polymorphic cytochrome P450 (CYP) 2D6 pathway. Two subpopulations of metabolizers have been identified; Extensive metabolizers [EMs] and Poor metabolisers [PMs] [8]. Those persons who are believed as "poor metabolizers" (PM) of CYP2D6 drugs (about $7 \%$ of the Caucasian population) have been shown to have average peak atomoxetine concentrations up to 5 -fold higher and total plasma exposure of atomoxetine 10-fold higher than persons who have extensive (normal) metabolic (EM) activity. Half life of atomoxetine in poor metabolizers was 22 hours and 5.2 hours in extensive metabolizers $[1,10]$. The half-life of the active metabolite, 4 hydroxyatomoxetine, has been found to range from 6 to 8 hours in extensive metabolizers, and from 34 to 40 hours in poor metabolizers [8].

\section{Excretion}

Majority of the atomoxetine dose is excreted primarily as 4hydroxyatomoxetine-O-glucuronide in the urine, with approximately $13-22 \%$ and $1-2 \%$ eliminated in the faeces of PMs and EMs, respectively. At steady state the mean apparent plasma clearance of atomoxetine was approximately $0.036 \mathrm{~L} / \mathrm{h} / \mathrm{kg}$ for PMs versus 0.373 $\mathrm{L} / \mathrm{h} / \mathrm{kg}$ for EMs. Less than $3 \%$ of drug is excreted unchanged in urine $[10,11]$.

\section{Efficacy}

The first double blind, placebo controlled study to determine efficacy of atomoxetine in ADHD in adults was reported its superiority over placebo in reducing ADHD symptoms and that it was well tolerated. 1This was trailed by an open label pilot study and a dose ranging study in children and adolescents, both of which were in favour to atomoxetine in demonstrating its efficacy and tolerability $[12,13]$. Atomoxetine statistically proves its efficacy comparable to methylphenidate in the treatment of ADHD, as established in a 10 week, open label study [14]. Children who met the DSM-IV criteria for confirming diagnosis of ADHD, similar reductions in ADHD symptoms were seen in both the atomoxetine and methylphenidate treatment groups. Results of Michelson et al study demonstrates that improvements in social and family functioning and self-esteem were superior among atomoxetine treated patients compared with those in the placebo group. Atomoxetine offers 24 hour continuous symptom relief, with the resulting treatment benefits during school time, family hours, and sleep may create a significantly higher potential for psychosocial improvements to child and family. Although majority of studies were consistent in demonstrating the effectiveness of atomoxetine, a few limitations exist. In particular, there is a limited data relating to the long term outcome of trials, although longer term data are emerging. In addition, limited data is available comparing atomoxetine to stimulants [1].

\section{Efficacy in children and adolescents}

Studies on efficacy of atomoxetine in children with ADHD first emerged in 2001. Once- or twice-daily dosing of atomoxetine was beneficial in the short-term treatment of ADHD in children and adolescents, as noticed in several well designed placebo-controlled trials [4.15-20]. A large randomized controlled study on 297 children and adolescents with ADHD demonstrated superior efficacy of 1.2 $\mathrm{mg} / \mathrm{kg} /$ day and $1.8 \mathrm{mg} / \mathrm{kg} /$ day doses compared with placebo. All subjects initially started with $0.5 \mathrm{mg} / \mathrm{kg} /$ day, in two divided doses, and increased at weekly intervals. Efficacy was assessed using parent and investigator ADHD rating scales; the $1.2 \mathrm{mg} / \mathrm{kg}$ and $1.8 \mathrm{mg} / \mathrm{kg}$ doses were significantly superior to placebo at reducing ADHD symptoms, with similar improvement for inattentive and hyperactive/impulsive subtype symptoms [10]. Long term treatment of atomoxetine demonstrated efficacy in patients with ADHD. A single morning dose was shown to be effective into the evening, and withdrawal of atomoxetine was not associated with symptom rebound. Presence of co-morbid disorders (Oppositional defiant disorder, Major depressive disorder, Autism spectrum disorder, Anxiety and Tic disorder) does not alter the efficacy of atomoxetine, and symptoms of the co-morbid disorders were not influenced or were improved by atomoxetine administration [21,25]. Atomoxetine also significantly improved Health Related Quality Of Life (HR-QOL) than standard current therapy [9]. 
An observational open-label study on 627 ADHD children with mean age of 11 years, evaluated the treatment efficacy of atomoxetine. Treatment duration ranged from 0 to 89 weeks with an average span of 21.2 weeks. The primary outcome measure of efficacy was the Physician Global Impression: ADHD Severity (PGI-ADHD-S) scale, which had a mean severity decrease of 0.91 (95\% CI:- 1.00 to $-0.82, \mathrm{p}$ 0.001). Symptoms were improved in 59 to $69 \%$ of subjects [10].

A prospective, open study was conducted on 604 children and adolescents at 33 sites. Symptoms were assessed with the ADHD Rating Scale and the Child Health Questionnaire. ADHD scores were found to reduce by $56.7 \%$, with $69 \%$ of patients rated as having no or minimal symptoms [26].

A randomized, placebo-controlled study of 153 children with ADHD evaluated the efficacy of once daily dose of atomoxetine. Medication up to $1.8 \mathrm{mg} / \mathrm{kg}$ daily was administered for 7 weeks. Teacher ratings using the ADHD Rating Scale-IV, Teacher Version were utilized based on an investigator phone interview with the teacher. Significant improvement was seen in total as well as the inattentive and hyperactive-impulsive subscales in the group receiving atomoxetine [27].

In a 3 month randomized trial, 176 patients including ages 8-17 with ADHD and an anxiety disorder (generalized anxiety disorder, separation anxiety disorder, or social phobia disorder) were randomized to receive atomoxetine or placebo. After completion of two week treatment with placebo, the atomoxetine group received 1.2 $\mathrm{mg} / \mathrm{kg}$ daily in two divided doses. Symptoms were measured with the ADHD Rating Scale, the Paediatric Anxiety Rating Scale, and the Multidimensional Anxiety Scale for Children. Significant improvement was noticed in ADHD symptoms as well as noticeable improvement of anxiety compared with placebo [8].

\section{Efficacy in adults}

Michelson et al. conducted two randomized, placebo-controlled studies on the use of atomoxetine in adults with 280 patients at 17 sites in study I and 256 patients at 14 sites in study II. Atomoxetine doses varied from 60 to $120 \mathrm{mg}$ /day. Symptom improvement was assessed with the Conner's Adult ADHD Rating Scales (CAARS) Total ADHD Symptom Score. Both studies reported significant reductions in CAARS scores, with study II concluding significant improvement in social, family, and work function as measured by the Sheehan Disability Scale [8]. Two similar studies using randomized, doubleblind, placebo-controlled designs over a treatment period of 10 -weeks were conducted in adults with DSM-IV-defined ADHD as assessed by clinical history and confirmed by a structured interview (study I, n = 280; study II, $\mathrm{n}=256$ ). The primary outcome measure was a comparison of atomoxetine and placebo using repeated measures mixed model analysis of post baseline values of the CAARS. In each study, atomoxetine was effective over placebo in reducing both inattentive and hyperactive and impulsive symptoms as assessed by primary and secondary measures. Dropouts for adverse events among atomoxetine patients were under $10 \%$ in both studies. This study concluded that atomoxetine appears to be an efficacious treatment for adult $\mathrm{ADHD}$ and possess minimal abuse potential and may be an advantage for many patients [15].

\section{Comparison with stimulants}

In a randomized, prospective open-label trial including 228 subjects, treatment was randomized as atomoxetine $(\mathrm{n}=184)$ or methylphenidate treatment $(n=44)$ for 10 weeks. Medication efficacy was assessed with the ADHD-IV Rating Scale-parent version only. Both groups showed significant improvements in ADHD symptoms [8].

Wilens et al. completed a 2-phase, 7-week open study in children between the ages of 6 to 17 years. However, children were not included based upon prior lack of response to stimulant treatment. After monotherapy with atomoxetine for 4 weeks, Osmotic controlled Release Oral delivery System methylphenidate (OROS MPH) was added to the treatment regimen to partial responders to atomoxetine. Patients were assessed various outcomes including ADHD, executive functioning and adverse effects. Of fifty subjects treated with the combination therapy, 41 subjects completed the study with 9 drop outs. ADHD-RS was reduced by $40 \%$ from the beginning of combination treatment through the end of study (from 21.14 \pm 9.9 to $\left.12.8 \pm 9.7, \mathrm{t}=6.5, \mathrm{p} \_0.0001\right)$. In addition, there was a significant reduction in the Clinical Global Index of ADHD severity from moderate to mild ADHD as well as improvements in executive functioning [10].

A 10 week open label study was conducted on Children with ADHD, and children were randomized to open-label atomoxetine or methylphenidate. Response was measured with the ADHD-IV Rating Scale. Both drugs show significant improvement in inattentive and hyperactive-impulsive symptom clusters as assessed by parents and investigators. This study concluded that atomoxetine is associated with therapeutic effects comparable to those of methylphenidate [14].

In a large placebo-controlled, double-blind study, patients with age group between 6-16 with ADHD, any subtype, were randomly assigned to receive $0.8-1.8 \mathrm{mg} / \mathrm{kg}$ per day of atomoxetine $(\mathrm{N}=222)$, $18-54 \mathrm{mg} /$ day of osmotically released methylphenidate $(\mathrm{N}=220)$, or placebo $(\mathrm{N}=74)$ for 6 weeks. The response rates for both atomoxetine (45\%) and methylphenidate (56\%) were noticeably superior to that for placebo (24\%), but the response to osmotically released methylphenidate was superior to that for atomoxetine [28].

The short term studies may not provide full efficacy profile of atomoxetine. Reports of two studies Comparing atomoxetine, methylphenidate and mixed amphetamine salts extended release medication demonstrates, each stimulant medication is superior effectiveness over atomoxetine, while a 10-week study by Kratochvil et al reported similar effectiveness with either atomoxetine or immediate-release methylphenidate.

The Newcorn et al trial is the only large, controlled study to offer within-subject data (crossover) characterizing treatment response to atomoxetine in children who did not respond to stimulant treatment during the study itself ( $40 \%$ decrease in ADHD rating scale). After 6 weeks of initial treatment, under double blinded conditions, children treated with OROS MPH were switched to atomoxetine. Study results were in favour to atomoxetine, stating that the 70 youths who did not respond to OROS MPH in the trial, $43 \%$ subsequently responded to atomoxetine [10].

\section{Safety and tolerability}

Atomoxetine has been shown to be well tolerated in most of the patients. Most of the adverse drug reactions associated with atomoxetine treatment was mild or moderate, and there was a very low incidence of serious adverse events. The most frequently occur side-effects include headache, GI discomfort, slightly elevated diastolic 
blood pressure, sweating, nausea, vomiting, anorexia, weight loss, irritability, insomnia, and sedation. Urinary retention, erectile dysfunction, dysmenorrhoea, and decreased libido were reported rarely in adults. Very rare but significant side-effects that have been reported include elevated liver enzymes, and motor tics [6,8].

A placebo controlled study conducted to compare the impact of abrupt discontinuation following acute treatment with atomoxetine in children, adolescents, and adults reported that sudden withdrawal of atomoxetine therapy did not result in the development of an acute discontinuation syndrome and was well tolerated. Because atomoxetine does not increase dopamine in the nucleus accumbens, a region associated with excitation and pleasurable behaviours, it is not expected to have abuse potential. This may make atomoxetine more preferable. In addition, atomoxetine does not aggravate tics and it is beneficial in patients with co morbid affective disorders [1].

\section{Atomoxetine and aggression/psychosis}

In a meta-analysis of aggression/hostility-related trials of atomoxetine, in less than $2 \%$ of patients events of aggression were noted and were more frequent in children. If mood changes occur, additional symptoms such as pressured speech and decreased need for sleep must be evaluated [10].

\section{Atomoxetine and hepatic injury}

Hepatic injury is very rarely reported with atomoxetine treatment. In an investigation of case reports identified by a computerized search that contained potential hepatic events, of the 7962 paediatric and adult patients treated with atomoxetine in clinical trials, 41 were identified as requiring further analysis. Of those 41 cases, none progressed to liver failure, and most of these events were mild increases in aminotransferase (ALT) and aspartate aminotrasferase (AST) levels. Metabolic idiosyncrasy or induced autoimmune hepatitis is expected to be major cause of atomoxetine induced liver injury. Since hepatic injury is rare with atomoxetine treatment it is not currently recommended for physicians to do routine monitoring of liver function tests during treatment [10]. Patients with compromised hepatic function will require a decrease in dosing. Clearance of atomoxetine was significantly reduced in 10 adult patients with hepatic impairment compared with 10 adult controls. The degree of impairment associated with reduction in clearance of atomoxetine. The adjusted dose should be reduced by $25 \%$ in patients with mild to moderate hepatic insufficiency to $50 \%$ in patients with severe hepatic impairment [8].

\section{Atomoxetine and the cardiovascular system}

There is no current evidence on cardiovascular risk in healthy children with therapeutic doses of atomoxetine treatment. However, treatment at usual doses in children and adolescents with structural cardiac abnormalities or other serious heart problems may exacerbate the cardio vascular risk and also sudden death has been reported. Although some serious cardio vascular abnormalities alone carry an increased risk of sudden death, in general atomoxetine should not be used in children or adolescents with known serious structural cardiac abnormalities, cardiomyopathy. Before initiating treatment with atomoxetine in children, obtaining clinical history includes assessment for a family history of early sudden death and physical exam, as well as obtaining information about possible cardiac symptoms including chest pain and syncope might helpful to assess presence of cardiac disease. It is well established that atomoxetine may raise heart rate in both younger and older children $[1,10]$.

\section{Atomoxetine and CNS toxicity}

Incidence of seizures as an adverse event with atomoxetine use has been estimated at between 0.1 and $0.2 \%$ of the patients. Somnolence appeared more frequent followed by dizziness among atomoxetine recipients and insomnia appeared more frequent among stimulant recipients $[9,11]$.

\section{Atomoxetine and Suicidal tendency}

FDA has given black box warning for Atomoxetine with the following warning: "Atomoxetine increased the risk of suicidal ideation in short-term studies in children or adolescents with Attention Deficit/Hyperactivity Disorder (ADHD)" [29]. Short term placebo controlled studies in children and adolescents demonstrated high risk of suicidal tendency in patients those using atomoxetine compared with placebo [10] Bangs et al. conducted an acute, doubleblind, and placebo- or active comparator-controlled trials, and demonstrated that although uncommon, suicidal tendency was significantly more frequent in pediatric ADHD patients treated with atomoxetine compared to those treated with placebo [30].

\section{Atomoxetine and overdose}

Numerous studies have examined the toxicology of atomoxetine in patients exposed to an overdose of atomoxetine. Dose of $6.25 \mathrm{mg} / \mathrm{kg}$, to $249 \pm 326 \mathrm{mg}$, and above $1200 \mathrm{mg}$ have been reported as a toxic range. In some reports, no adverse drug reactions appeared with atomoxetine over dose. In others, higher rates of potential complications were found with a dose of greater than $2.8 \mathrm{mg} / \mathrm{kg}$ or 200 $\mathrm{mg}$, but no case lead to death [31-34].

\section{Clinical Indications and Uses}

\section{Oppositional defiant disorder}

The most common co-morbid condition of ADHD is ODD, which occurs in $40 \%$ to $60 \%$ of children with ADHD. One study which reported statistically significant improvement in ODD may have benefited from twice-daily dosing, allowing for better control of oppositional symptoms during the evening hours [10].

\section{Tic disorders}

It is well established that stimulant medications have been associated with the onset or aggravation of a tic disorder, atomoxetine may offer benefit in children with ADHD and co morbid tic disorders; Tourette's syndrome (TS), and/or simple motor tic disorder. In most of the studies the efficacy and tolerability of atomoxetine in tic and motor disorders is well demonstrated [10].

\section{Childhood anxiety disorders}

In addition to co morbid ODD and tics, nearly one third of children with ADHD have co morbid anxiety disorders. The large controlled study of ADHD and co morbid anxiety was demonstrates significant improvement Mean Paediatric Anxiety Rating Scale (PARS) total score and also reported that significant reduction in independently assessed 
anxiety symptoms using both clinician-rated and self-rated measures for atomoxetine [10].

\section{Drug interactions}

Since atomoxetine is metabolized by CYP2D6 enzyme, interactions can occur with drugs that are inhibitors of this enzyme such as paroxetine, fluoxetine, and quinidine, citalopram, escitalopram, bupropion, sertraline, chlorpromazine, hydroxyzine, and clomipramine. Twenty-two healthy subjects with rapid metabolism of the 2 D6 system were received $20 \mathrm{mg}$ of atomoxetine to steady state. 20 mg of paroxetine was added for 17 days with co administration with atomoxetine for the last 6 days. Paroxetine markedly increased the peak plasma concentration of atomoxetine by 3.5 -fold and half-life of atomoxetine by 2.5 -fold. There was no change in paroxetine level with the addition of atomoxetine. It is suggested to start treatment at standard doses and while increasing the critical care must be taken. Dexamethasone and rifampin were found to be the inducers of CYP2D6 enzyme, but no interactions were noticed between atomoxetine and 2D6 inducers. Co-administration of atomoxetine with albuterol may raise heart rate and/or blood pressure. Coadministration with a monoamine oxidase inhibitor may increase the risk of a hypertensive crisis [8].

\section{Contraindications}

Atomoxetine should be used with caution in patients with hypertension, tachycardia, cerebral or cardiovascular disease. Dosage adjustment may be essential for patients with hepatic failure or those receiving CYP2D6 inhibitors (paroxetine, fluoxetine or quinidine). The drug is not recommended in patients with narrow angle glaucoma [11].

\section{Dosage-administration}

The starting dose of atomoxetine in children with ADHD is 0.5 $\mathrm{mg} / \mathrm{kg} /$ day and increased after 4 days to $1.2-1.4 \mathrm{mg} / \mathrm{kg} /$ day [35]. It is recommended to initiate therapy with $40 \mathrm{mg}$ once daily of atomoxetine in adults with $\mathrm{ADHD}$, further which can then be increased to a target dose of $80 \mathrm{mg} /$ day or a maximum of $100 \mathrm{mg} /$ day if necessary [11]. Atomoxetine might take 4 weeks to show its effect. Patients should be monitored for Weight, height (for growing children and adolescents), blood pressure, and pulse at every visit. Liver function tests are recommended if there is report of fatigue, jaundice, right upper quadrant pain, or flu-like illness. If the patient has pre-existing hypertension, tachycardia, or cardiovascular disease precautions must be taken, as atomoxetine has not been studied in patients with these conditions and the medication is known to slightly increase blood pressure and pulse [8].

\section{Conclusion}

Atomoxetine is a non-stimulant drug and the first drug to be licensed for the treatment of ADHD in adults and children. Atomoxetine has found to be having a significant role in the treatment of children and adults who do not respond or develop side effects to stimulants. As per our review, majority of the studies have been shown that atomoxetine is superior or as equal as methylphenidate in its efficacy. In most of the studies atomoxetine has shown to be well tolerated with minimal adverse events and no abuse potential, because it acts selectively on pre synaptic norepinephrine receptors and less affinity towards other receptors. Atomoxetine offers other advantages such as once daily dosage and mild anti anxiety effect and can be considered as alternative first line therapy to methylphenidate in patients with ADHD and with other co morbid tic disorders.

\section{Reference}

1. Barton J (2005) Atomoxetine: a new pharmacotherapeutic approach in the management of attention deficit/hyperactivity disorder. Arch Dis Child 90: 26-29.

2. David M, Douglas F, Joachim W, Douglas K, Katherine, et al. (2001) Atomoxetine in the Treatment of Children and Adolescents With Attention-Deficit/Hyperactivity Disorder: A Randomized, PlaceboControlled, Dose-Response Study. Pediatrics 108: 1-9.

3. Michihiro T, Yasushi T, Taro G, Hironobu I, Kazuhiko S, et al. (2011) An open-label, dose-titration tolerability study of atomoxetine hydrochloride in Japanese adults with attention-deficit/hyperactivity disorder. Psychiatry Clin Neurosci 65: 55-63.

4. David M, Albert JA, Joan B, Charles C, David D, et al. (2002) Once-Daily Atomoxetine Treatment for Children and Adolescents with Attention Deficit Hyperactivity Disorder: A Randomized, Placebo-Controlled Study. Am J Psychiatry; 159: 1896-1901.

5. Gordon B (2009) Drug treatments for attention-deficit hyperactivity disorder in young people. Advances in psychiatric treatment 15: 162-171.

6. Dusan K, Amanda K, Lilly H (2008) Treatment of adults with attentiondeficit/hyperactivity disorder. Journal of Neuropsychiatric Disease and Treatment 4: 107-121.

7. Michihiro T, Yasushi T, Kosuke Y, Takashi H, Hironobu I, et al. (2009) A Randomized, Double-Blind, Placebo-Controlled Study of Atomoxetine in Japanese Children and Adolescents with Attention-Deficit/Hyperactivity Disorder. J Child Adolesc Psychopharmacol 19: 341-350.

8. Marcialee L (2006) Atomoxetine: a novel treatment for child and adult ADHD. Journal of Neuropsychiatric Disease and Treatment 2: 455-466.

9. Karly PG, Gillian MK (2009) Atomoxetine: a review of its use in Attention-Deficit Hyperactivity Disorder in children and adolescents. Paediatric drugs 11: 203-226.

10. Paul H, Katherine MC, Elizabeth M, Cassandra G, Daniel G (2009) Atomoxetine for the treatment of attention-deficit/hyperactivity disorder in children and adolescents: a review. Neuropsychiatric Disease and Treatment 5: 215-226.

11. Dene S, Greg LP (2004) Atomoxetine; a review of its use in adults with Attention-Deficit Hyperactivity Disorder. Drugs 64: 205-222.

12. Christopher JK, Daryl B, Martin H, Natalie B, Diane M, et al. (2001) An Open-Label Trial of Tomoxetine in Pediatric Attention Deficit Hyperactivity Disorder. J Child Adolesc Psychopharmacol 11: 167-170.

13. Spencer T, Biederman J, Heiligenstein JH, Wilens T, Faries D, et al.(2001) An open-label, dose-ranging study of atomoxetine in children with attention deficit hyperactivity disorder. J Child Adolesc Psychopharmacol 11: 251-65.

14. Christopher JK, John HH, Ralf D, Thomas JS, Joseph B, et al. (2002) Atomoxetine and Methylphenidate Treatment in Children With ADHD: A Prospective, Randomized, Open-Label Trial. J Am Acad Child Adolesc Psychiatry 41: 776-784.

15. Margaret W, Rosemary T, Christopher K, David D, Jesus V, et al. (2005) A Randomized, Placebo-Controlled Study of Once-Daily Atomoxetine in the School Setting in Children with ADHD 44: 647-655.

16. Michelson D, Faries D, Wernicke J, Douglas K, Katherine K, et al. (2001) Atomoxetine in the treatment of children and adolescents with attentiondeficit/ hyperactivity disorder: a randomized, placebo-controlled, doseresponse study. Pediatrics 108: 83-91. 
Citation: Rajan KV, Sreenivas PS, Surya Durga Devi PS, Vineela P, Pasam R, et al. (2014) A Review on Atomoxetine in the Treatment of Attention Deficit Hyperactivity Disorder. J Psychiatry 17: 1000146. doi:10.4172/1994-8220.1000146

Page 6 of 6

17. Spencer T, Heiligenstein JH, Biederman J, Faries DE, Kratochvil CJ, Conners CK et al. (2002) Results from 2 proof-of-concept, placebocontrolled studies of atomoxetine in children with attention-deficit/ hyperactivity disorder. J Clin Psychiatry 63: 1140-7.

18. Gau SS, Huang YS, Soong WT, Chou MC, Chou WJ, et al. (2007) A randomized, double-blind, placebo-controlled clinical trial on once-daily atomoxetine in Taiwanese children and adolescents with attention-deficit/ hyperactivity disorder. J Child Adolesc Psychopharmacol 17: 447-60.

19. Brown RT, Perwien A, Faries DE, Kratochvil CJ, Vaughan BS (2006) Atomoxetine in the management of children with ADHD: effects on quality of life and school functioning. Clin Pediatr 45: 819-27.

20. Kelsey DK, Sumner CR, Casat CD, Coury DL, Quintana H, et al. (2004) Once-daily atomoxetine treatment for children with attention-deficit/ hyperactivity disorder, including an assessment of evening and morning behavior: a double-blind, placebo-controlled trial. Pediatrics 114: 1-8.

21. Bangs ME, Hazell P, Danckaerts M, Hoare P, Coghill DR, et al. (2008) Atomoxetine for the treatment of attention-deficit/hyperactivity disorder and oppositional defiant disorder. Pediatrics; 121: 314-20.

22. Bangs ME, Emslie GJ, Spencer TJ, Ramsy JL, Carlson C, et al. (2007) Efficacy and safety of atomoxetine in adolescents with attention-deficit/ hyperactivity disorder and major depression. J Child Adolesc Psychopharmacol 17: 407-20.

23. Geller D, Donnelly C, Lopez F (2007) Atomoxetine treatment for pediatric patients with attention-deficit/hyper-activity disorder with comorbid anxiety disorder. J Am Acad Child Adolesc Psychiatry 46: 1119-27.

24. Arnold LE, Aman MG, Cook AM, Andrea NW, Kristy LH, et al. (2006) Atomoxetine for hyperactivity in autism spectrum disorders: placebocontrolled crossover pilot trial. J Am Acad Child Adolesc Psychiatry 45: 1196-205.

25. Allen AJ, Kurlan RM, Gilbert DL, Coffey BJ, Linder S L, et al. (2005) Atomoxetine treatment in children and adolescents with ADHD and comorbid tic disorders. Neurology 65: 1941-9.
26. Jan KB, Marina D, Christopher G, Alessandron Z, Katza B, et al. (2004) A prospective, open-label assessment of atomoxetine in non-north American children and adolescents with ADHD. Eur Child Adolesc psychiatry 13: 249-257.

27. David M, Lenard A, Thomas S, Frederick WR, Scott AW, et al. (2003) Atomoxetine in adults with ADHD: two randomized, placebo-controlled studies. A journal of psychiatric neuroscience and therapeutics 53: $112-120$.

28. Jeffrey HN, Christopher JK, Albert JA, Charles DC, Dustin DR, et al. (2008) Atomoxetine and Osmotically Released Methylphenidate for the Treatment of Attention Deficit Hyperactivity Disorder: Acute Comparison and Differential Response. Am J Psychiatry 165: 721-730.

29. Strattera- Food and Drug administration.

30. Bangs ME, Tauscher-Wisniewski S, Polzer J, Zhang S, Acharya N, et al. (2008) Meta-analysis of suicide-related behavior events in patients treated with atomoxetine. J Am Acad Child Adolesc Psychiatry 47: 209-18.

31. Stojanovski SD, Robinson RF, Baker SD, Casavant MJ, Hayes JR, et al. (2006) Children and adolescent exposures to atomoxetine hydrochloride reported to a poison control center. Clin Toxicol 44: 243-247.

32. Spiller HA, Lintner CP, Winter ML (2005) Atomoxetine ingestions in children: a report from poison centers. Ann Pharmacother 39: 1045-1048.

33. Lovecchio F, Kashani J (2006) Isolated atomoxetine (Strattera) ingestions commonly result in toxicity. J Emerg Med 31: 267-268.

34. Forrester MB (2006) Adult atomoxetine ingestions reported to Texas Poison Control Centers, 2003-2005. Ann Pharmacother 40: 2136-2141.

35. Sunil K (2005) Attention deficit hyperactivity disorder: A review for family physicians. Indian journal of medical sciences 59: 547-556. 